\title{
Caracterización histológica del tejido conectivo sometido a fuerzas ortodóncicas.
}

Rational basis for the systemic

treatment of periimplantitis.
Base racional para 0

tratamento sistêmico da periimplantite.
Fecha de Recepción

I5 de junio de 2012
Aceptado para su publicación

27 de febrero de 2013
Ma. Alejandra Gili

Prof. Adjunta. Histología y Embriología. FOUNNE.

Email: magili@odn.unne.edu.ar

Ma.Victoria Aguirre Profesora Titular. Química Biológica II. FACENA. UNNE.

Ma. Silvia Almirón JTP. Anatomía Patológica. FOUNNE

Karina Latyn

Auxiliar Docente I ra.Fundamentos de Ortodoncia. FOUNNE

\section{Resumen}

La investigación histológica ha permitido establecer conexión entre los hallazgos histológicos y el planeamiento profiláctico o terapéutico sirviendo de sustento como principio básico para la toma de decisiones en la clínica. Este proyecto de tipo descriptivo-analítico tiene por objeto describir las características del tejido conectivo periodontal y de los fibroblastos sometidos a fuerzas ortodóncicas mediante microscopía óptica con técnicas de coloración histológica convencionales (Hematoxilina-Eosina).

Las muestras de tejido periodontal se obtuvieron de pacientes que concurrieron al Servicio de Ortodoncia de la Facultad de Odontología de la UNNE y en los cuales como parte del tratamiento está indicada la extracción dentaria. Las fuerzas aplicadas fueron de tipo leve con arcos iniciales elásticos, arco de Niti 0,12; O arco de acero trenzado, twinflex o coaxial. El tiempo de aplicación de la fuerza varió entre 15 y 30 días.

Los preparados histológicos obtenidos a partir de las muestras evidencian a los fibroblastos dispuestos paralelos a los haces de fibras lo que hace suponer su intensa actividad remodeladora durante la aplicación del movimiento ortodóncico maneteniendo su morfología celular. Hay presencia de aislados focos de hemorragia y focos inflamatorios leves.

\section{Palabras claves}

Ortodoncia - células del tejido conectivo - periodonto - histomorfología celular. 
REVISTA FACULTAD DE ODONTOLOGÍA

ISSN No 1668-7280 - Vol. VI № 2 - 2013

29
INVESTIGACIÓN

Caracterización histológica del tejido

conectivo sometido a fuerzas ortodóncicas.

\section{Abstract}

Histological research has allowed a connection from the histologic and planning prophylactic or therapeutic support serving as a basic principle for decision-making in the clinic. This project is a descriptive-analytical is to describe the characteristics of the periodontal connective tissue and fibroblasts subjected to orthodontic forces using light microscopy with conventional histological staining techniques (hematoxylin-eosin).

Samples of gingival and periodontal connective tissue was obtained from patients who attended the Service of Orthodontics, Faculty of Dentistry UNNE and which is indicated for extraction. The applied forces were mild-type initial elastic arches, Niti arch 0.12 , or twisted steel arch, twinflex or coaxial. The time of application of force ranged from 15 to 30 days.

In histological preparations fibroblasts are evident parallel to the fiber bundles which suggests an intense remodeling activity during application of orthodontic movement keep in cell morphology. Are isolated focus of hemorrhage and mild inflammatory.

\section{Keywords}

Orthodontics - connective tissue cells - periodontal - cellular histomorphology.

\section{Resumo}

Investigação histológica permitiu uma conexão do profilática histológica e de planejamento ou apoio terapêutico servindo como um princípio básico para a tomada de decisão na clínica.

Amostras de tecido conjuntivo gengival e periodontal foram obtidos de pacientes atendidos no Serviço de Ortodontia da Faculdade de Odontologia UNNE e onde a extração é indicada. As forças aplicadas foram leves do tipo inicial arcos elásticos, Niti 0,12 arco, ou arco de aço retorcido, twinflex ou coaxial. $O$ tempo de aplicação da força variou de 15 a 30 dias.

Em fibroblastos preparações histológicas são paralelos evidentes para os feixes de fibras, o que sugere uma atividade intensa remodelação durante a aplicação da morfologia celular movimento ortodôntico maneteniendo são isolados focos de hemorragia e leve focos inflamatórios.

\section{Palavras chave}

Ortodontia - células do tecido conjuntivo periodontal - histomorfologia celular.

\section{Introducción}

La aplicación de fuerzas ortodóncicas para movilizar piezas dentarias es caracterizado por procesos de remodelación en los tejidos dentarios y paradentarios, incluyendo la pulpa dental, el ligamento periodontal, el hueso alveolar y el tejido gingival. Cuando estos tejidos se encuentran expuestos a diferentes grados o magnitudes, frecuencia y duración de la carga mecánica, expresan marcados cambios microscópicos y macroscópicos. Los movimientos dentarios producidos fisiológicamente o durante la erupción dentaria difieren de los generados durante un tratamiento ortodóncico. Los movimientos dentarios fisiológicos son procesos lentos, en cambio los movimientos ortodóncicos pueden ocurrir rápida o lentamente, dependiendo de las características físicas de las fuerzas aplicadas y esto determinará la respuesta biológica de los tejidos peridentarios.

La respuesta biológica a la aplicación de fuerzas ortodóncicas del ligamento periodontal principalmente de sus células mas abundantes los fibroblastos es el objeto de estudio del presente trabajo de investigación.

La investigación histológica ha permitido establecer conexión entre los hallazgos histológicos y el planeamiento profiláctico o terapéutico sirviendo de sustento como principio básico para la toma de decisiones en la clínica. Este proyecto de tipo descriptivo-analítico tiene por objeto describir las características del tejido conectivo periodontal y de la población de fibroblastos sometidos a fuerzas ortodóncicas mediante microscopía óptica con técnicas de coloración histológica convencionales (Hematoxilina-Eosina).

Resulta de interés la realización de una investigación de este tipo para identificar como responde el tejido conectivo del ligamento periodontal a la aplicación de fuerzas contribuyendo en la elección del tratamiento más adecuado.

Los fibroblastos humanos son células de origen mesenquimal predominantes en el tejido conectivo gingival y periodontal, están comprometidos en el funcionamiento normal y anormal de estos tejidos, en su desarrollo, manteni- 
miento, reparación y defensa.

Trabajos como el de Lehm I permiten entender claramente esta relación ya que estableciendo una correlación entre la presencia de bacterias periodontopatógenas y el avance de un estado de gingivitis hacia periodontitis crónica o agresiva, fundamenta con el conocimiento histológico la terapéutica mas apropiada a seguir.

La investigación bibliográfica pone de manifiesto una importante variedad de trabajos científicos realizados con fibroblastos epidérmicos y pulpares sometidos a los estudios mas diversos que incluyen determinación de morfología, variaciones de los mismos a la acción de diferentes drogas o materiales dentales, estudios comparativos en diferentes estadios de patologías.

En una revisión bibliográfica de la Pontificia Universidad Javeriana ${ }^{2}$, el autor concluye que el movimiento dental ortodóncico es una reacción biológica de los tejidos dentoalveolares a aplicaciones intencionales de fuerzas externas, lo cual significa que este tipo de terapias mecánicas deben tener en cuenta las restricciones y posibilidades del sistema biológico.

Otros autores ${ }^{3}$ reportan que no existe gran diferencia entre las reacciones hísticas que ocurren en el movimiento dentario fisiológico y las observadas en el movimiento ortodóncico. Sin embargo como los dientes se mueven más rápidamente durante el tratamiento, los cambios generados por las fuerzas ortodóncicas son más marcados y extensos.

Además durante el tratamiento ortodóncico debe tenerse presente los mecanismos biológicos implicados en el mismo ya que existen evidencias de que ciertas sustancias químicas son capaces de influir sobre la actividad celular afectando la remodelación de los tejidos de sostén del diente.

El uso de fuerzas ortodóncicas y los efectos biológicos que estas producen en los tejidos dentarios son objeto de variadas investigaciones4. Por ejemplo la aparición y extensión de reabsorciones radiculares en molares de ratas que fueron sometidas a fuerza ortodóncicas y que habían sido inducidas a enfermedad periodontal. Los resultados obtenidos por métodos histomorfométricos determinaron el porcentaje de áreas de reabsorción radicular, y sobre cortes histológicos se observaron que existe mayor reabsorción radicular al aplicar la fuerza y que la magnitud de la fuerza aplicada es proporcional a la extensión de la reabsorción radicular y al número de odontoclastos viables.

Otro estudio ${ }^{5}$ también realizado en molares de ratas con periodontitis inducida revela que una vez controlada la infección periodontal la aplicación de fuerzas ortodóncicas contribuye al aumento del volumen del hueso alveolar y por consiguiente al mejoramiento de su calidad.

Odontólogas de la Facultad de Odontología de la UNNE ${ }^{6}$ han explicado mediante un trabajo de investigación el modo mas eficaz de distalamiento de caninos utilizando diferentes cantidades de fuerzas ortodóncicas con distintos elementos. Han tomado muestras de tejido óseo en distintos períodos de evolución del tratamiento y han detectado como efectos indeseables a nivel histopatológico la presencia de hemorragias e infiltrados.

\section{Material y Método}

Se tomaron muestras de tejido gingival y periodontal de pacientes sistémica y periodontalmente sanos en los cuales se requiere de exodoncia de las piezas dentarias que fueron previamente sometidas a fuerzas ortodóncicas. Los pacientes concurren al Servicio de Ortodoncia de la Facultad de Odontología donde se les realiza:

- Anamnesis y descripción clínica general del paciente: examen de cráneo y cara y examen intraoral

- Análisis cefalométrico

- Análisis de modelos y montaje en articulador

- Registros fotográficos.

- Radiografías panorámicas, telerradiografías y periapicales.

Estas instancias permiten realizar un diagnóstico y abordar un plan de tratamiento adecuado. En los casos clínicos que el plan de tratamiento incluya la exodoncia de algunas piezas dentarias estas son previamente sometidas a fuerzas leves a fin de facilitar su extracción disminuyendo el daño que puedan sufrir los tejidos peri dentarios como el ligamento periodontal. Algunos casos en los que se recomienda la extracción dentaria en ortodoncia son: cuando hay falta de espacio en la arcada para la correcta ubicación de las piezas dentarias en el plano de oclusión, en pacientes 
con mordidas abiertas o biprotrusión, y cuando es necesario conseguir armonía facial, recuperar la simetría de la cara o mejorar el prognatismo mandibular.

Las fuerzas aplicadas son de tipo leve con arcos iniciales elásticos, arco de Niti 0, I2; O arco de acero trenzado, twinflex o coaxial. El tiempo de aplicación de la fuerza varia entre 15 y 30 días aproximadamente.

Al paciente se lo puso en total conocimiento del plan de tratamiento, como así también de la finalidad que persigue esta investigación razón por la cual se toma la muestra de tejido correspondiente, requiriendo su expreso consentimiento escrito.

La toma de muestras se realizó teniendo en cuenta las medidas tanto de asepsia como de antisepsia necesarias en el procedimiento para evitar cualquier tipo de contaminación.

Las muestras de tejido obtenido corresponden a las piezas dentarias extraídas:

- Paciente I: tejido periodontal de pieza dentaria 35

- Paciente 2: tejido periodontal de pieza dentaria 25

- Paciente 3: tejido periodontal de pieza dentaria 35

- Paciente 4: tejido periodontal de pieza dentaria 24

- Paciente 5: tejido periodontal de pieza dentaria 25

Una vez obtenida la muestra y protocolizada la misma se fijó en Formaldehído al 10\% (Formol) en un recipiente con un volumen 30 a 60 veces mayor del de la pieza, a temperatura ambiente y con un $\mathrm{pH}$ compatible con los tejidos de 7 a 7,4. El material se envió al Servicio de Anatomía Patológica de la FOUNNE.

Posteriormente se realizó el procesamiento de rutina de coloración con Hematoxilina-Eosina $(\mathrm{H} / \mathrm{E})$ : deshidratación con sucesivos baños en alcohol etílico a $70^{\circ}, 90^{\circ}$ y $100^{\circ}$. La inclusión en parafina comprende también 4 baños concluyendo con la obtención de la muestra encerrada en un bloque de parafina pura. Este bloque o taco fue modelado obteniéndose finas secciones con micrótomo que serán fijadas en un portaobjeto. A continuaciones procedió a desparafinizar los cortes realizando dos baños de xileno de 10 a 15 min. cada uno. Eliminamos el solvente por suce-

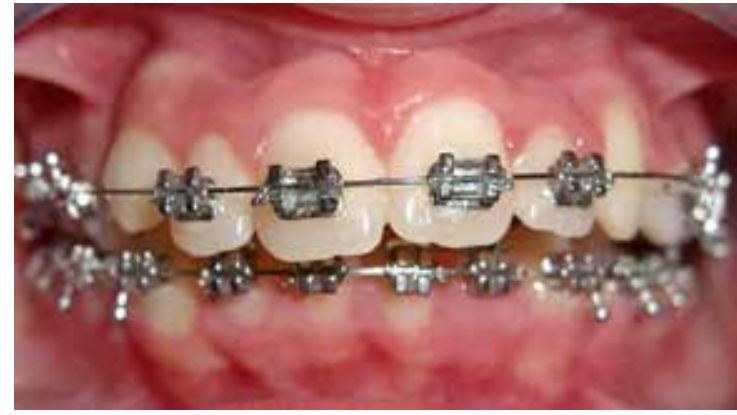

Figura. Vista Clínica.

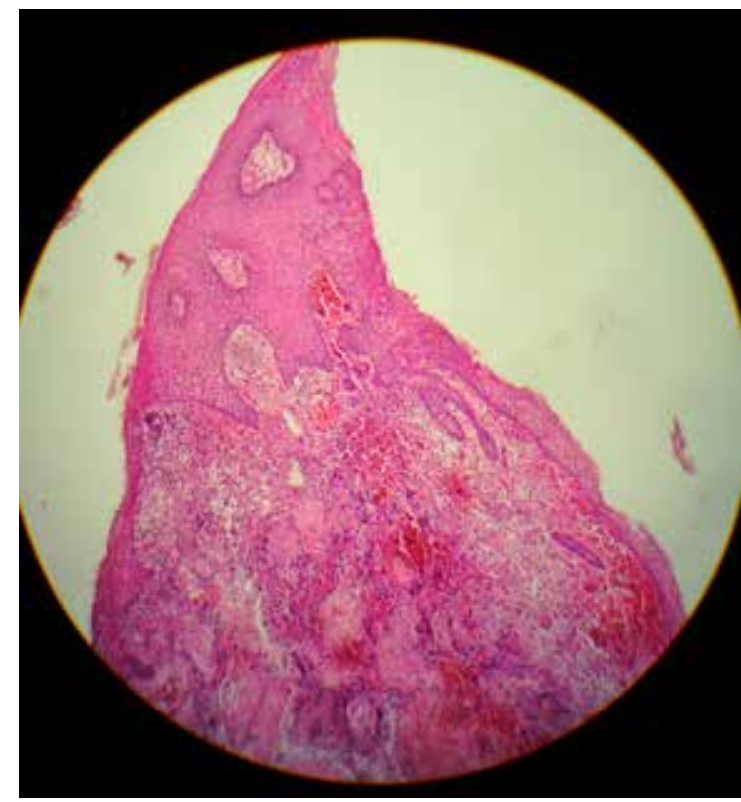

Figura. 10 X. Tejido Gingival.

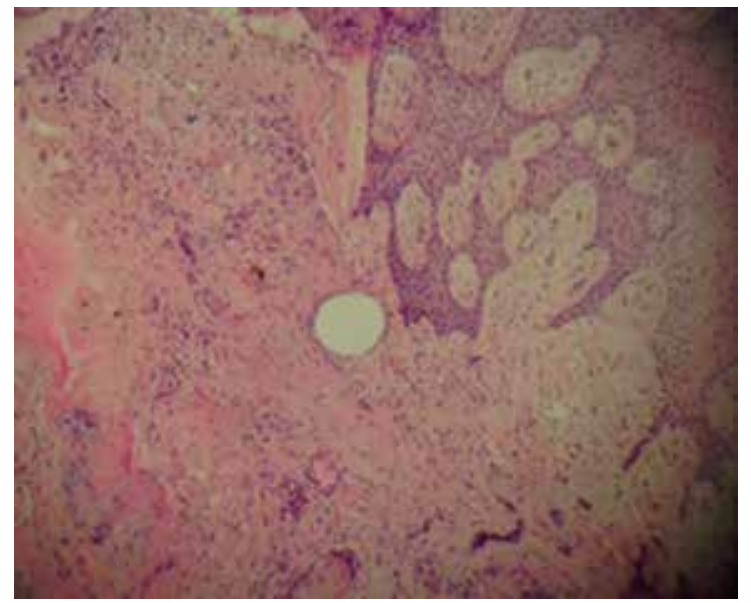

Figura. 40 X. Tejido Gingival. 
sivos baños en: alcohol de $100^{\circ}, 96^{\circ}, 70^{\circ}$ de I a 2 min. cada uno. La hidratación de los cortes se realzó en agua destilada durante 1 a $2 \mathrm{~min}$. Tinción nuclear en Hematoxilina durante 2 a 12 min. de acuerdo a la formula utilizada. Viraje de la hematoxilina: en agua corriente hasta desprendimiento total del color ( 3 a 5 min.). Lavado en agua destilada o corriente. Coloración citoplasmática con eosina al $0.5 \%$ o en una mezcla de eosina/floxina al $0.5 \%$ durante 15 a 30 seg. Lavado en agua destilada. Deshidratación, aclaración y montaje

Las muestras obtenidas fueron registradas fotográficamente en Microscopio Olympus CH30 con sucesivos aumentos de 40X, I00X y 400X.

\section{Resultados}

Los fibroblastos se evidencian paralelos a los haces de fibras lo que hace suponer su intensa actividad remodeladora de los haces de fibras colágenas durante la aplicación del movimiento ortodóncico. Los núcleos mantienen su forma elíptica de localización central y grande. A nivel del tejido conectivo de variedad fibrosa se evidencian aislados focos de hemorragia como así también tejido conectivo laxo perivascular.

La respuesta del tejido periodontal a una fuerza mantenida de tipo leve durante un período de 30 días determina alteraciones en el flujo sanguíneo por variación del diámetro en los vasos sanguíneos (dilatación) y que obliga a la pieza dentaria a cambiar su posición en el espacio periodontal. Es posible observar focos inflamatorios leves. Los fibroblastos mantienen su morfología celular y se encuentran organizados en patrones al azar. Hay presencia de escasos brotes de colágeno levemente separados por fibroblastos.

\section{Discusión}

En el estudio realizado por Gutiérrez Salinas y col. ${ }^{7}$ para determinar la presencia de laminina, se aplicaron en el ligamento periodontal fuerzas ortodóncicas en premolares de sujetos clínicamente sanos y al término de tres semanas,previa extracción dentaria, se obtuvieron las muestras del tejido para determinar la presencia de laminina por medio de Western Blot. Los resultados obtenidos reflejaron que existen cambios a nivel molecular en el ligamento periodontal de dien-

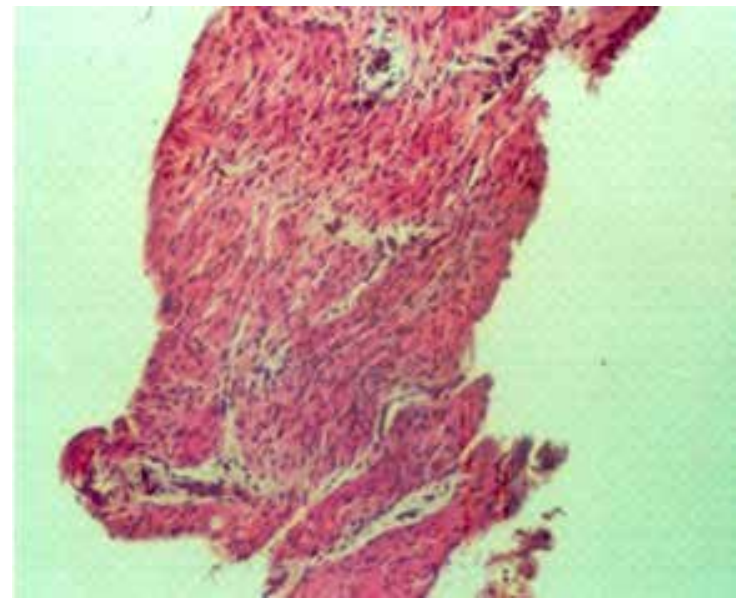

Figura. I00X Tejido Periodontal

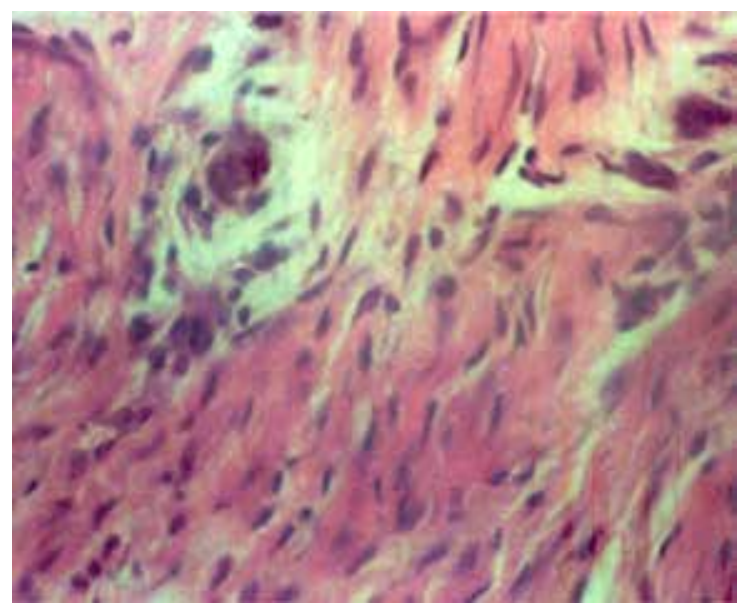

Figura. 400X Tejido Periodontal.

tes que fueron sometidos a fuerzas ortodóncicas como lo es una disminución estadísticamente significativa en la presencia de laminina.

Estudios de comparación ${ }^{8}$ entre fibroblastos del ligamento periodontal y de la encía humanas obtenidas de un mismo paciente y mantenidas in vitro demostraron una mayor producción de colágeno en células del ligamento periodontal y altos niveles de fosfatasa alcalina. Esto permite entender mejor el papel de estas células en los procesos de regeneración y formación de cemento, hueso alveolar y tejido conectivo. 
INVESTIGACIÓN

Caracterización histológica del tejido

conectivo sometido a fuerzas ortodóncicas.

\section{Bibliografía}

I. Lehm, Andreas. "Histología dentaria y periodontal: fundamentos para el tratamiento en odontología". Quintessence (Edición española). Volumen XX, No. 2 (I29-135).

2. González, O. "Fenómenos clínicos e histológicos asociados a la magnitud de la fuerza ortodóncica". En www.javeriana.edu.co

3. Guercio de Dinatale, Elisabetta. Biología del movimiento dentario ortodóntico: Revisión de conceptos. Acta Odontológica Venezolana. [online]. ene. 200I, vol.39, no.I [citado 25 Febrero 2008], p.6I-65. Disponible en la World Wide Web: <http:// www.scielo.org.ve/scielo.php?script=sci_arttext\&pid=S000 16365200100010001 I \&lng=es\&nrm=iso>. ISSN 000 I-6365.

4. Garat, J. A, Gordillo, M. E., Ubios, A.M "Effect of orthodontic forces on root resorbtion in molars submitted to experimental periodontitis". Acta Odontológica Latinoamericana. Vol 17. n I-2 (pág 3-7). 2004.

5. Garat, J. A., Martín, A., Gordillo, M. E., Ubios, A.M "Bone response to different strenght orthodontic forces in animals with periodontitis". Journal of Periodontal Research. Vol 40. issue 6. (pág 44I-445). Diciembre 2005.

6. Lewintre de Borjas, M y Collantes, Carmen. "Distalamiento de caninos: Reacción de los tejidos peridentarios a las distintas fuerzas ortodóncicas con distintos elementos". Revista de la Facultad de Odontología. UNNE. NI. (18-22). 1993.

7. Gutiérrez Salinas, J. y colab. "Cambios en la expresión de laminita en el ligamento periodontal en dientes sujetos a tensión ortodóntica en humanos”. Revista de la Asociación Dental Mexicana. Vol. LXII, No. 5 Septiembre-Octubre 2005 pp 17I-176. En: http://www.medigraphic.com/espanol/e-htms/e-adm/e-od2005/e-od05-5/em-od055c.htm.

8. Somerman, M. J y colab. "A comparative study of human periodontal ligament cells and gingival fibroblasts". Journal of Dental research. 67. issue I. (66-70). Enero 1998

9. Theilig,C.:y colab. "Effects of Mechanical Force on Primary Human Fibroblasts Derived from the Gingiva and Periodontal Ligament”. Journal Dental Research. Vol 80 (8). I777-1780. 200 I 